The Geneva Papers on Risk and Insurance, 8 (No 27, April 1983), 95-96

\title{
Response to Professor Barre's Lecture
}

\author{
by Robert L. Carter *
}

I would like to congratulate Professor Barre on a stimulating lecture in which he so clearly presents the policy issues confronting governments and societies today in their pursuit of security in a risky world. I agree with much of his analysis, so what I have to say is in the nature of comment on detail rather than a criticism of his basic thesis.

Professor Barre rightly draws attention to the fact that society is faced with an optimisation problem of a type familiar to the risk managers of large corporations who frequetly have to decide in the light of the costs involved in controlling risks how much secuirity they not only desire but can afford. For a firm, profit maximisation and security as measured by certainty of financial outcomes are mutually exclusive objectives. ${ }^{1}$ Individuals have similar choices ; they can either aim to achieve the highest possible, though uncertain, income or incur the costs involved in securing a more certain, though consequently lower, net income. Collectively it is not possible during a period of economic recession for a society both to maintain the material living standards of its members and to provide for all the same standard of social protection as they enjoyed in the past.

This relationship between standards of living and security can be illustrated by reference to an aspect of security that Professor Barre has not mentioned, that is physical risk control which involves measures to reduce either the probability of occurrence of uncertain, loss-producing events or their severity. Not only is society demanding greater financial security, it also wants higher standards of safety at work, on the roads and in the products and services it consumes. Measures to improve safety, however, usually involve additional costs which if not fully offset by extra revenue or reduced losses, ultimately will either be passed on in higher prices or cause a fall in profits leading possibly to some goods and services no longer being produced. Furthermore the higher are the standards of safety demanded the greater will be the barriers to innovation and economic development, so impairing the ability of society to provide the level of financial security it may desire.

Professor Barre in his discussion of collective risk refers to the risks associated with the intensification of international competition. That competition can be distorted by differences in national risk handling policies in regards to both physical control and

* Professor at the University of Nottingham.

1 R. L. Carter, "Risk Management : a British Point of View", Zeitschrift für die Gesamte Versicherungswissenschaft, vol. 1/2, 1978. 
risk financing which can change comparative advantages. An industry may lose its competitive advantage to foreign firms located in countries where there is less concern about safety and the adequate compensation of accident victims. Equally firms may seek to sell in less regulated markets products which in other countries would be banned on grounds of safety.

Although I subscribe in principle to the plea made for greater choice in welfare, with social security merely providing a socially acceptable minimum standard of income available to all regardless of ability to pay, I do have some practical reservations. How far the private insurance industry could or should participate in the provision of extra security is a matter for debate. What should society do about the individual who chooses not to buy additional insurance protection and then suffers loss? To automatically provide assistance beyond the person's social security entitlement would undermine the whole policy, but to refuse help may display lack of compassion. Moreover, paradoxically it is often those who have the greatest need for insurance that can least afford to buy it.

Also relevant to the debate is Kulp's ${ }^{2}$ distinction between fundamental and particular risks. A major risk confronting individuals today is unemployment. Largely that is a fundamental risk over which the individual has little control. However, as unemployment rates rise world-wide is it an insurable risk which can be handled by private insurance? According to Baruch Berliner's analysis ${ }^{3}$ the answer is no.

Professor Barre's reference to the effect of unemployment benefit on willingness to work and the black economy is an example of the problem familiar to insurers moral hazard. Similar examples could be drawn from other areas of social security, such as sickness benefit and health care. However, there is no reason to believe that the problem can be solved by introducing choice into welfare. It is true that operating in a competitive market a private insurer who is better able than his competitors to control the extra claims costs attributable to moral hazard will have a competitive advantage. Nevertheless even private insurers cannot totally eliminate such behaviour : it is noteworthy that Arrow and Pauly ${ }^{4}$ in their economic analysis of moral hazard took the case of health care in America where the risk is privately insured.

Finally regarding systems of financing retirement pensions $I$ think that this is not just a distribution problem between the working and retired sections of the population. It is also a question of whether a funded or a pay-as-you-go scheme is more likely to contribute to the growth of the overall level of economic activity. The Wilson Committee in Britain came down on balance in favour of funded schemes concluding that they at least provide the opportunity for higher saving and investment. ${ }^{5}$

Despite these reservations, Professor Barre has presented a challenge to private insurance industries which I hope they will seize.

2 C. A. Kulp, Casualty Insurance, Ronald Press, 1956.

3 Baruch Berliner, Limits of Insurability of Risks, Prentice Hall, 1982.

4 K. J. Arrow, "Uncertainty and the welfare economics of medical care", American Economic Review, vol. 53, 1963 ; and M. V. Pauly, "The economics of moral hazard", American Economic Review, June 1968.

5 Report of the Committee to Review the Functioning of Financial Institutions, para. 332, Cmnd. 7937, HMSO, 1980. 